\title{
ANALISIS SPASIAL EKOLOGIKAL SUMBERDAYA LAHAN DI PROVINSI DAERAH ISTIMEWA YOGYAKARTA
}

\author{
Suratman Worosuprodjo \\ Fakultas Geografi, Universitas Gadjah Mada \\ Bulaksumur-Yogyakarta. Telp. 0272-902332/Fax. 0274-589595 \\ E-mail: ratman_woro@yahoo.com
}

\begin{abstract}
Land resources is an important geographical aspect related to landuse allocation for human living. The aim of this research is to study the spatial ecological analysis for land resources in related to landuse type in the Province of Yogyakarta Special Region, the approach used in the research is landscape analysis based on geomorphological mapping, topographic map at scale 1:100000. Land resources potential in the study area can be classified based on landscape such as volcanic landscape, fluvial landscape, marine and eolion landscape, karst landscape (Gunung Sewn), structural - denudational landscape (Balur Agung). Landuse can be alocated based on the landscape condition, and limitation. Land limitation such as slope steepness, soils, natural hazard, water resources in each landscape can be used as detrminant factors in the landuse plan.
\end{abstract}

Keywords: land reources, spatial ecological, analysis

\section{PENDAHULUAN}

Sumberdaya lahan merupakan sumberdaya alam yang terbentuk dan berkembang oleh pengaruh faktor-faktor iklim, geologi/geomorfologi, tanah, hidrologi wilayah, penggunaan lahan dan manusia. Selain faktor tersebut keadaan flora dan fauna juga memiliki peran dalam proses perkembangan sumberdaya lahan.

Leser dan Rood (1991) menjelaskan bahwa kehidupan manusia, tanaman dan hewan memerlukan bentanglahan sumberdaya alam sebagai tempat hidup dan melaksanakan kegiatan/aktivitas kehidupannya. Kehidupan manusia untuk bermukim dan melaksanakan aktivitas hidupnya melalui pengolahan sumberdaya lahan untuk pertanian, perkebunan, perikanan, pariwisata dan jasa sangat ditentukan oleh aspek geografis dari sumberdaya lahan di suatu daerah.

Provinsi Daerah Istimewa Yogyakarta memiliki kondisi sumberdaya lahan yang beragam dan karakteristik/kualitasnya dapat dibedakan secara tegas berdasarkan tipologi bentanglahannya (Landscape Type). Ditinjau dari aspek geologis/ gemorfologis landsacpe type di wilayah Provinsi Daerah Istimewa Yogyakarta dapat dibentuk oleh proses gunungapi, solusional, fluvial, marin dan oalin, struktural denudasional.

Permasalahan yang ada di setiap bentanglahan tersebut di indentifikasi dan dideskripsi seperti masalah kekurangan air, erosi, banjir, longsor, bahaya gunungapi, gempa dan tsunami. Demikian juga potensi lahannya, bahwa di setiap bentanglahan 
juga tidak sama, sehingga bentuk penggunaan lahannya pun bervariasi. Marginalisasi lahan di DIY banyak dijumpai di zona Baturagung, Menoreh, karst Gunungsewu, perbukitan solusional Sentolo dan kawasan gumuk pasir.

Berdasarkan uraian masalah bentanglahan tersebut di atas maka analisis spasial - ekologikal sumberdaya lahan penting dilakukan sebagai pendekatan penatagunaan lahan yang diterapkan bagi atau untuk Pemerintah DIY.

Daerah studi analisis spasial ekologikal sumberdaya lahan di Provinsi DIY terletak pada $7^{0} 15^{\prime}-8^{0} 15^{\prime}$ Lintang Selatan dan $110^{\circ} 5^{\prime}-110^{\circ} 4^{\prime}$ Bujur Timur. Provinsi DIY memiliki luas $3185 \mathrm{Km}^{2}$ yang merupakan provinsi terkecil di Indonesia dengan batas :

Sebelah Selatan : Samudra Hindia

Sebelah Barat : Kab. Purworejo, Kab. Magelang

Sebelah Utara : Kab. Boyolali, Kab. Magelang

Sebelah Timur : Kab. Klaten dan Wonogiri
Secara administratif daerah ini terbagi menjadi 4 Kabupaten dan 1 Kota (lihat Tabel 1).

\section{METODE PENELITIAN}

Data yang digunakan dalam kajian ini meliputi karakteristik geomorfologi, geologi, tanah, air, penggunaan lahan yang dapat diperoleh dari interpretasi peta topografi, geologi/geomorfologi dan tanah dan citra landsat. Hasil analisis peta-peta tersebut bersifat kualitatif. Sebagai pendekatan studi adalah analisis spasial - ekologikal bentanglahan yang berbasis geomorfologi.

Klasifikasi bentanglahan di dasarkan pada analisis genetik bentanglahan (genetic landscape approach). Penyajian hasil analisis ditampilkan dalam bentuk diskripsi dan dilengkapi dengan tabel.

\section{HASIL DAN PEMBAHASAN}

\section{Bentanglahan Volkanik}

Bentanglahan volkanik yang berasal dari Gunungapi Merapi membentang dari

Tabel 1. Wilayah Administrasi Provinsi DIY

\begin{tabular}{|c|l|c|c|}
\hline No. & \multicolumn{1}{|c|}{ Kab/Kota } & Luas $\left.\mathbf{( K m}^{\mathbf{2}}\right)$ & Persentase (\%) \\
\hline 1 & Sleman & 575 & 18,1 \\
\hline 2 & Kota Yogyakarta & 32 & 1,1 \\
\hline 3 & Bantul & 503 & 15,8 \\
\hline 4 & Kulonprogo & 586 & 18,4 \\
\hline 5 & Gunungkidul & 1485 & 46,6 \\
\hline \multicolumn{2}{|c|}{ Jumlah } & 3185 & 100 \\
\hline
\end{tabular}

Sumber : BPS, DIY, 2006 
utara hingga ke selatan yang dibedakan menjadi kerucut dan kawah, lereng gunungapi, lereng kaki gunungapi dan dataran aluvial gunungapi. Karakteristik lerengnya mulai dari sangat curam $(>45 \%)$ hingga landai $(3-8 \%)$ dan datar $(<3 \%)$. Kondisi tanah di bagian lereng atas belum berkembang sedangkan di bagian bawah (di dataran aluvial gunungapi) mulai berkembang pelapukannya dari lahan induk material vulkanik. Sumberdaya air berasal dari air permukaan dan mata air gunungapi (spring belt). Sumberdaya yang didapat diexploitasi adalah pasir dan batu. Selain itu di kawasan lereng atas dan kerucut gunungapi rawan bencana gunungapi. Sebagai besar terdapat di Kabupaten Sleman.

\section{Bentanglahan Struktural - Denuda- sional}

Bentanglahan ini terdapat di zona Baturagung yang batuannya berumur tersier

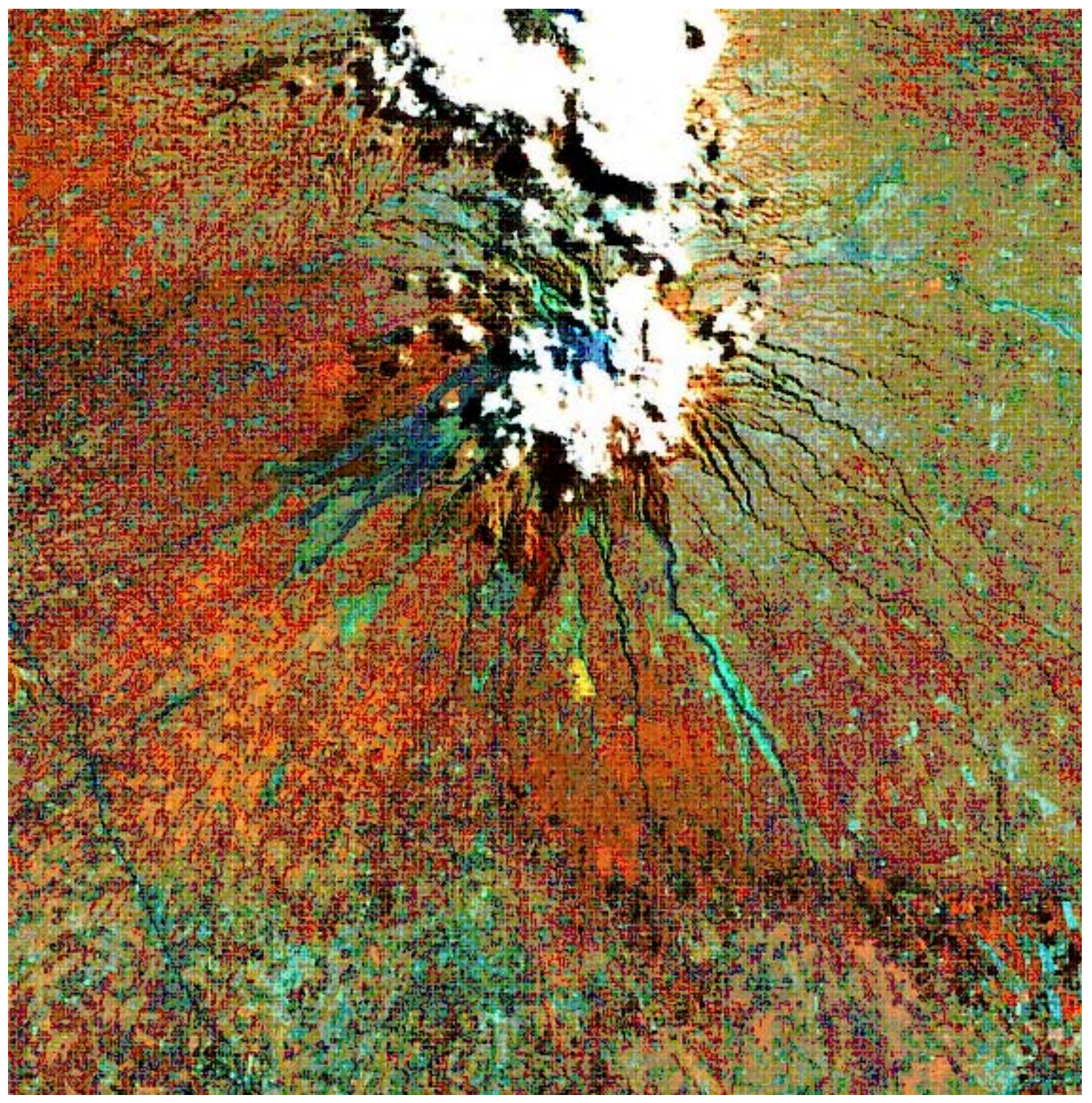

Gambar 1. Bentanglahan volkanik yang berasal dari Gunungapi Merapi Citra Landsat ETM + Komposit 457 
dan dapat dibedakan menjadi pegunungan denudasional, pegunungan struktural denudasional, perbukitan struktural denudasional, lereng kaki bukit. Bentanglahan ini juga terdapat di Pegunungan Menoreh di Kabupaten Kulonprogo. Kemiringan lereng bervariasi mulai dari sangat curam (> 45\%) di zona pegunungan dan perbukitan hingga landai - agak landai $\pm 8-15 \%$. Kondisi tanah mudah berkembang dengan pelapukan lanjut dan bahkan sebagian mengalami erosi dan longsor. Latosol dan litosol merupakan tanah yang dominan terdapat di bentanglahan struktural denudasional. Formasi batuan yang berpengaruh meliputi formasi Nglanggran,
Semilir, Sambipitu, Kebobutak, Breksi, Andesitik dan Nanggulan. Sumber bahan mineral galian yang dapat diexploitasi adalah termasuk golongan $\mathrm{C}$ (nir vital nir strategis). Sumber air yang utama berasal dari air hujan, air sungai dan mata air yang terbatas pada musim hujan (Suratman, 1997).

\section{Bentanglahan Perbukitan Struktural - Solusional}

Bentanglahan ini didominasi oleh kondisi topografi berbukit - bergelombang dengan lereng bervariasi dari agak curam (25 $-45 \%$ ) hingga landai $\pm 8 \%$ yang merupakan lereng kaki bukit. Formasi geologi pemben-

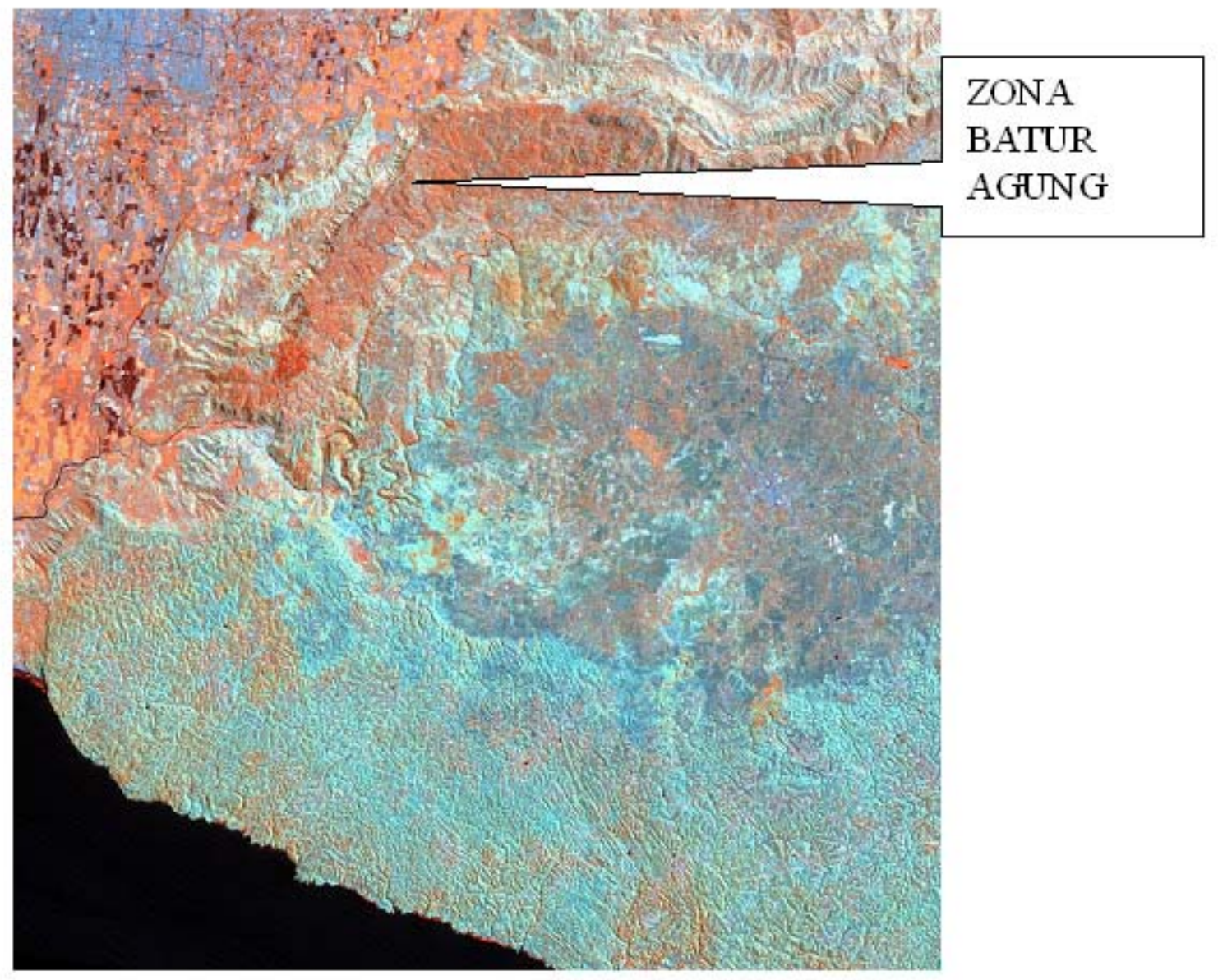

Gambar 2. Bentanglahan Struktural - Denudasional

Zona Batur Agung Citra Landsat ETM + Komposit 457 
tuknya adalah Formasi Sentolo. Grumosol, latosol, regosol meru-pakan tanah dominan yang berkembang di bentanglahan ini. Sumber air sangat terbatas dan tergantung dari air hujan, air tanah/mata air, proses solusional berjalan lambat dan erosi permukaan sangat sensitif sehingga tampak lahannya tidak produktif. Bahan galian yang dapat dimanfaatkan adalah batugamping, bentanglahan ini terdapat di wilayah Kabupaten Kulonprogo dan Bantul (Gambar 3).

\section{Bentanglahan Karst Gunung Sewu}

Bentanglahan ini berkembang dan terbentuk oleh pengaruh proses solusional intensif pada Pegunungan Sewu yang berbatuan batugamping. Bentanglahan yang lebih rinci meliputi : dataran tinggi kars,

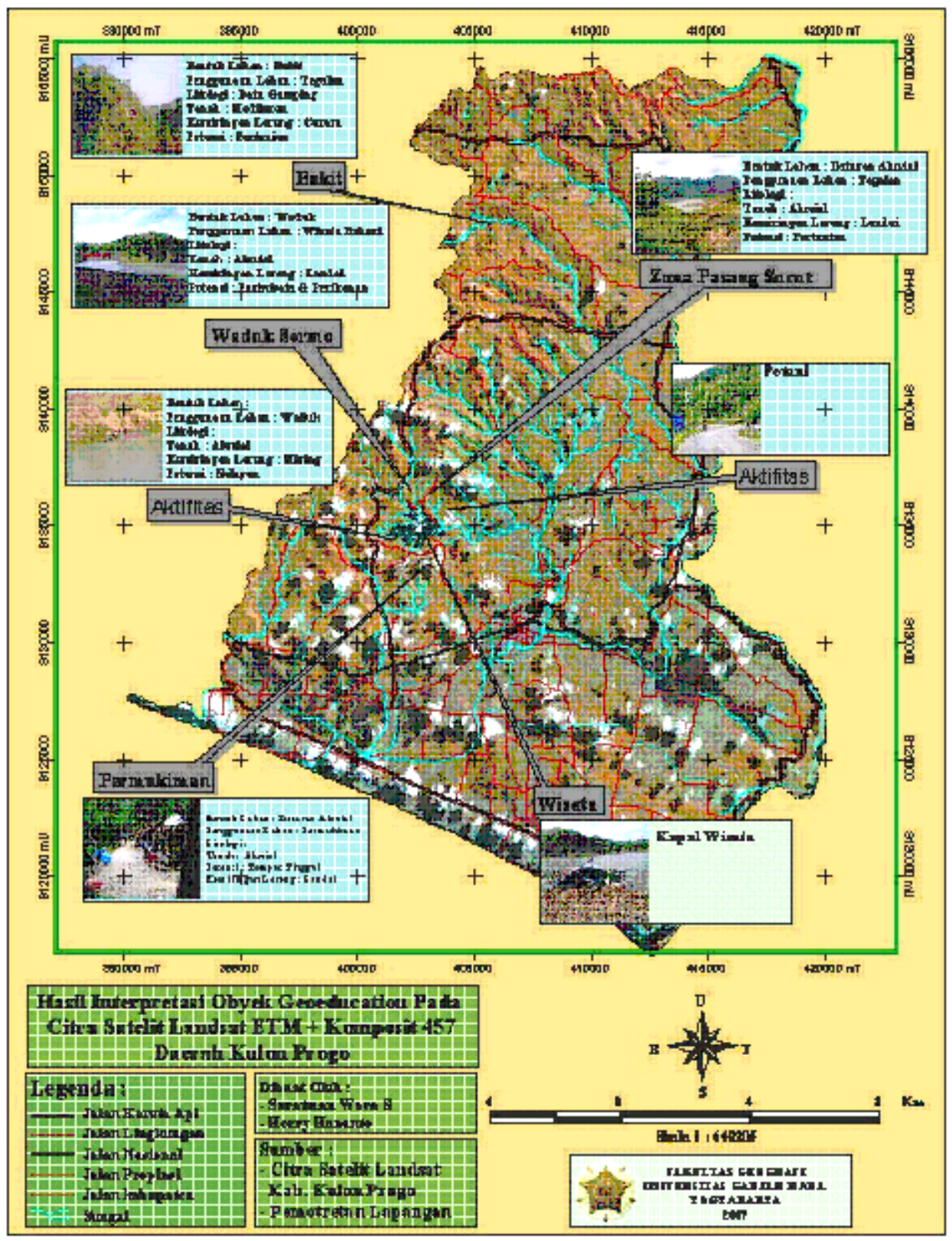

Gambar 3. Bentanglahan Struktural - Solusional

Daerah Kulon Progo Citra Landsat ETM + Komposit 457 
dataran aluvial kars, perbukitan karst, dolin dan upala serta memiliki keunikan bentangalam sungai bawah tanah, gua, stalagtit dan stalagmit.

Proses solusional dan erosi permukaan serta gerakan masa mempengaruhi pembentukan permukaan lahan. Lerengnya bervariasi dari datar hingga sangat curam tergantung dari kondisi topografi wilayahnya. Tanah yang dominan meliputi grumusol, molisol, litosol, mediteran. Sumber air yang dominan meliputi air hujan, air telaga, air dari sungai bawah tanah. Sumberdaya mineral yang utama adalah batugamping. Ancaman kekeringan selalu terjadi di musim kemarau sehingga lahannya kurang produktif (marginal). Bentanglahan ini terdapat di Kabupaten
Bantul dan Gunungkidul (Gambar 4). Karst Gunung Sewu

\section{Bentanglahan Dataran Aluvial}

Bentang lahan ini terbentuk dan berkembang pada lahan deposisional yang merupakan hasil endapan aluvial yang berada di dataran rendah di Kabupaten Bantul, Kulonprogo dan sebagian Sleman. Kondisi topografinya datar dengan lereng di bawah $8 \%$ dan sebagian besar kemiringan lereng $0-3 \%$. Selain bentanglahan yang terdapat meliputi teras sungai, dataran aluvial, dataran banjir, rawa belakang dan tanggul alam, sekitar dataran aluvial pantai tanahnya Aluvial, Kambisol, Grumusol, Gleisol yang produktif untuk pertanian, karena terdapat air permukaan yang mencukupi (Gambar 5).

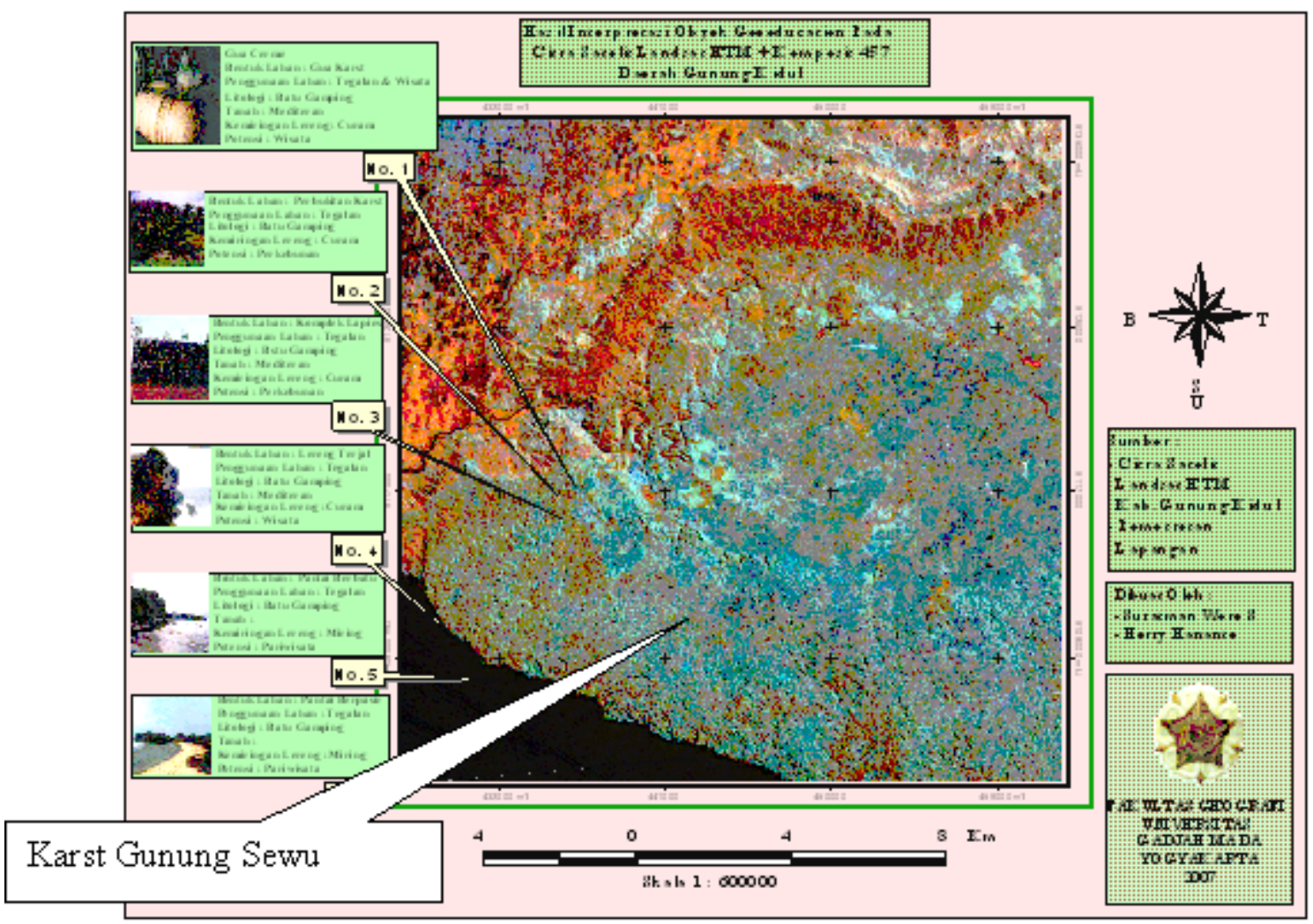

Gambar 4. Bentanglahan Karst Gunung Sewu

Citra Landsat ETM + Komposit 457 


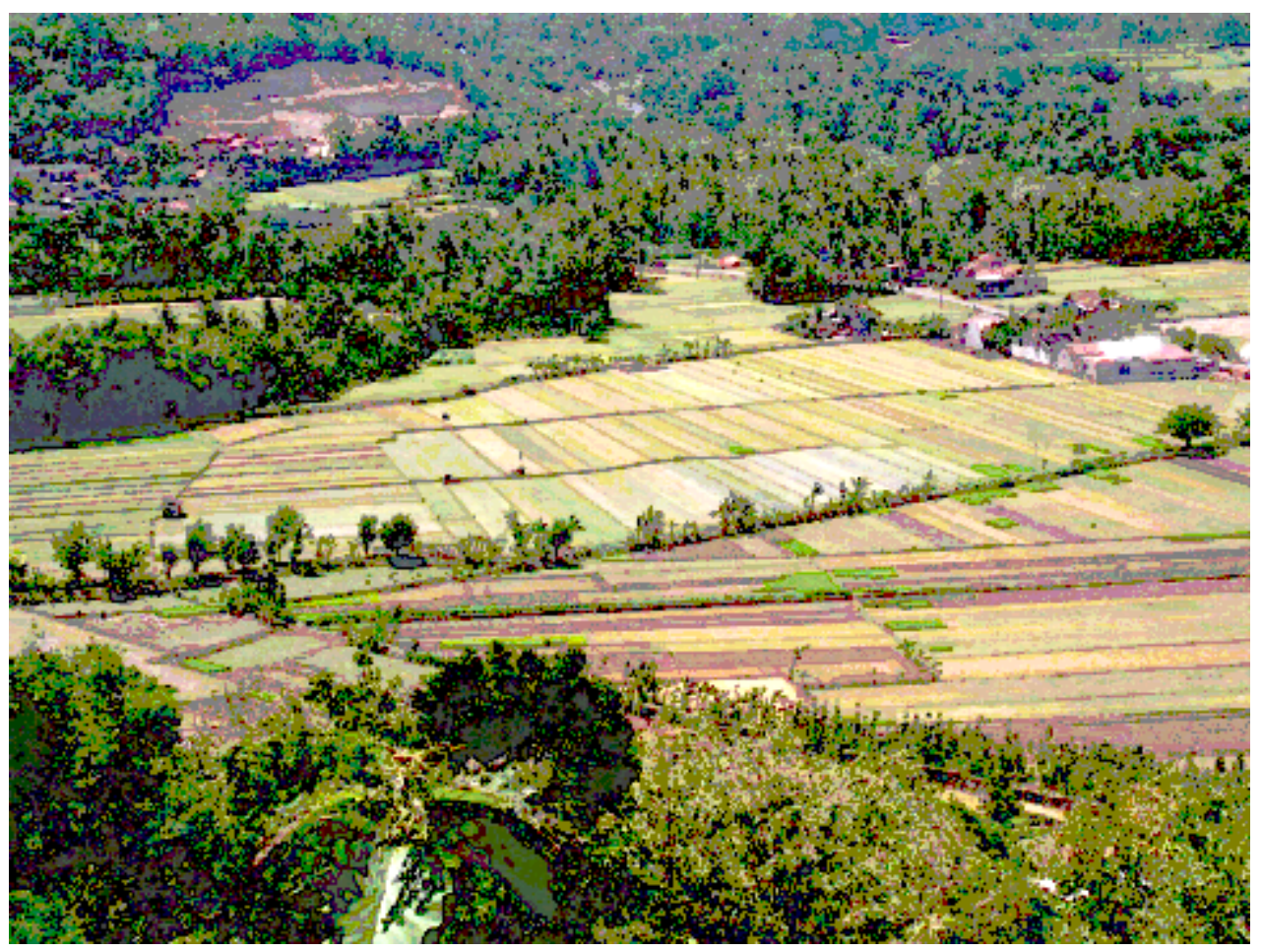

Gambar 5. Bentanglahan Dataran Aluvial (Persawahan)

\section{Bentanglahan marin dan Eolin}

Bentanglahan ini didominasi oleh adanya gumuk pasir dan bentang pantai di Kabupaten Bantul dan Kulonprogo serta teras-teras pantai di Kabupaten Gunungkidul. Kondisi topografi landai hingga curam/sangat curam (berbentuk tebing). Tanahnya relatif muda dan belum berkembang seperti Regosol. Kondisi air sangat terbatas dari air tanah sehingga lahannya tampak marginal dan bahkan tandus. Proses abrasi dan deposisi terjadi secara berselangseling tergantung kondisi bentang lahannya (Gambar 6).

\section{Pola Pemanfaatan Sumberdaya Lahan}

Berdasarkan pada analisis spasial ekologikal berbasis bentang lahan tersebut, maka pemanfaatan lahan dapat diarahkan sesuai dengan potensi dan hambatan yang ada di setiap bentang lahan seperti pada Tabel 2.
Pola pemanfaatan lahan yang disajikan pada Tabel 2 di atas dapat dipakai sebagai dasar perencanaan penggunaan lahan secara umum.

Sebagai dasar pertimbangan dalam penatagunaan lahan pada skala semi detil, dapat dijabarkan lebih lanjut atas dasar hambatan (faktor penghambat). Beberapa faktor penghambat dapat dijelaskan bahwa di kawasan kerucut dan lereng atas Gunungapi Merapi sangat rawan terhadap letusan gunungapi dan banjir lahar. Pada kawasan Pegunungan Menoreh dan Baturagung sangat rawan bencana longsor dan erosi, sedangkan di kawasan perbukitan kars Gunung Sewu sangat rawan bencana kekeringan, di kawasan pantai sangat rawan terhadap gempa tektonik dan tsunami. Di kawasan dataran banjir dan genangan. 


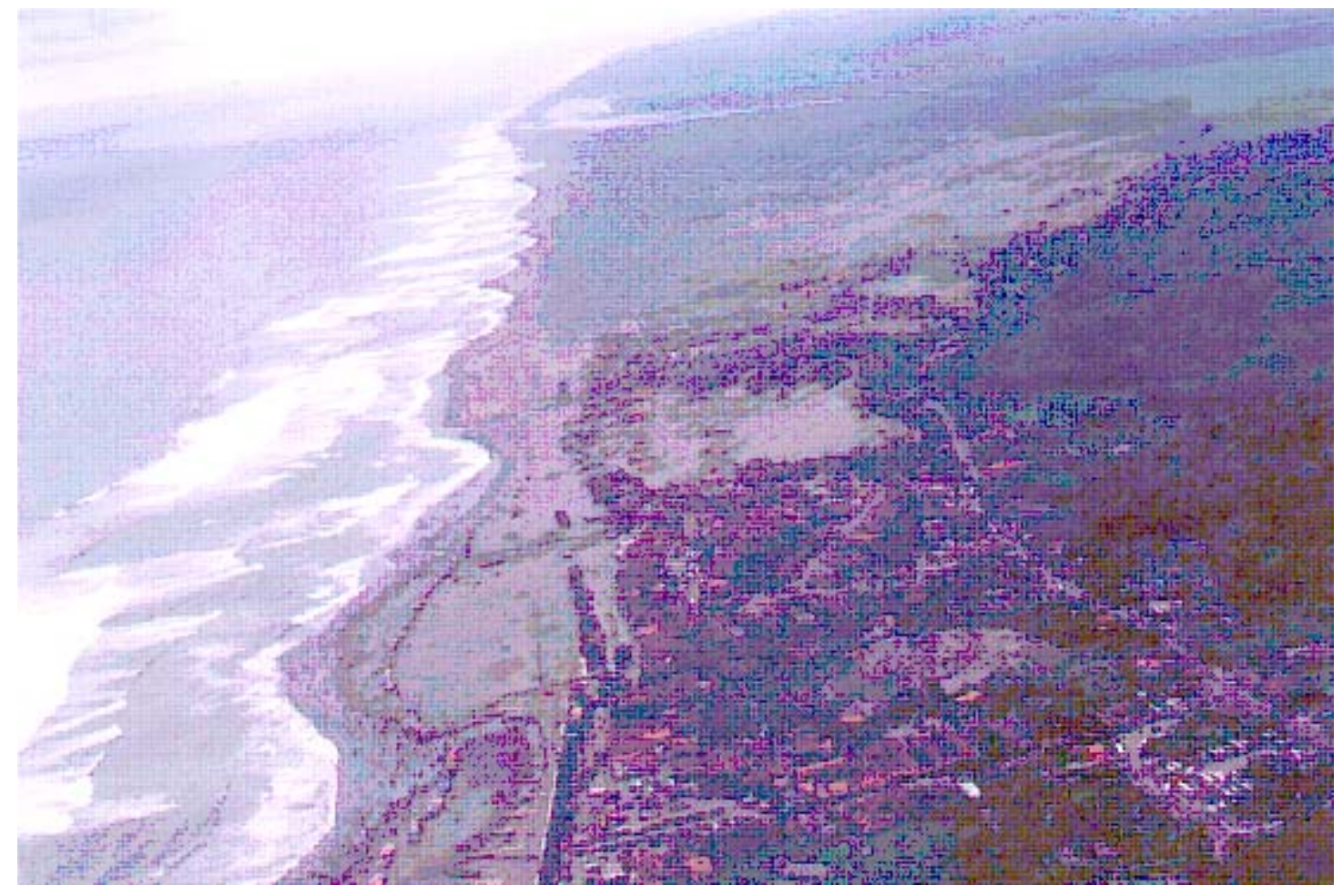

Gambar 6. Bentanglahan Marin dan Eolian (Gumuk Pasir)

Berdasarkan uraian di atas, maka Provinsi DIY memiliki keterbatasan sumberdaya lahan untuk pemanfaatan budidaya seperti permukiman, wisata, pertanian.

\section{KESIMPULAN}

1. Bentanglahan Provinsi DIY secara keruangan berpengaruh pada karakteristik dan kualitas sumberdaya lahan dan pemanfaatan lahan sesuai potensi dari permasalahnnya.

2. Bentanglahan di daerah studi dapat di kualifikasikan berdasarkan pendekatan "genetic - landscape" yang dibedakan menjadi bentanglahan vulkanik, bentanglahan struktural - denudasional, bentanglahan karst Gunung Sewu, bentanglahan struktural - solusional, bentang lahan datar aluvial, bentanglahan marin - eolin.
3. Pemanfaatanlahan untuk konservasi atau pelestarian fungsi ekosistem diarahkan di satuan kerucut gunung api, pegunungan dan perbukitan struktural - denudasional, perbukitan kars Gunung Sewu, zona gumuk pasir, dan pemanfaatan lahan untuk budidaya diarahkan pada bentang lahan dataran aluvial, lereng kaki gunungapi, lereng kaki pegunungan perbukitan dan perbukitan struktural - solusional.

\section{SARAN}

1. Rahabilitasi lahan dan reklamasi lahan perlu dilaksanakan pada zona lahan marginal dan konservasi di hutan lindung.

2. Pengendalian kerusakan lahan dan konservasi lahan pertanian ke non pertanian 


\section{DAFTAR PUSTAKA}

Harjadi, B. 2004. "Karakteristik Sumberdaya Lahan sebagai Dasar Pengelolaan DAS di Sub DAS Merawu, DAS Serayu". Forum Geografi, Vol. 18, No. 2, Desember 2004. Hlm 91-114.

BPS, 2006. Daerah Istimewa Yogyakarta Dalam Angka.

Darsiharjo. 2004. "Model Pemanfaatan Lahan Berkelanjutan di Daerah Hulu Sungai Cikapundung - Bandung Utara". Forum Geografi, Vol. 18, No. 1, Juli 2004. Hlm 3246.

Wahyu Santosa, L. 2005. "Identifikasi Kerusakan Lahan dan Cara Penanganannya di Zona Perbukitan Baturagung Kabupaten Gunung Kidul”. Forum Geografi, Vol. 19, No. 1, Juli 2005. Hlm 30-54.

Leser. H., and H. Rood, 1991. Landscape ecology - fundamentals, aims and perspectives. In Modern Ecology : Basic and Applied Aspects, edited by G. Esser and Overdieck, pp. 831844. Amsterdam/London/New York/Tokyo.

Worosuprojo, S., 2007. Pengelolaan Sumberdaya Lahan Berbasis Spasial Dalam Pembangunan Berkelanjutan di Indonesia. Pidato Pengukuhan Jabatan Guru Besar Pada Fakultas Geografi UGM.

Worosuprojo, S., 2006. Pemetaan Geomorfologi Provinsi Daerah Istimewa Yogyakarta. Fakultas Geografi UGM, Yogyakarta.

Worosuprojo, S., 1997. Ekologi Bentanglahan. Universitas Gadjah Mada Program Pasca Sarjana. Yogyakarta 